\title{
Beyond X-Chromosome Inactivation: The Oncogenic Facet of XIST in Human Cancers
}

\author{
Hamadi Madhi* and Myoung Hee Kim ${ }^{\dagger, * *}$ \\ Department of Anatomy, Embryology Laboratory, and Brain Korea 21 PLUS Project for \\ Medical Science, Yonsei University College of Medicine, Seoul 03722, Korea
}

Long-non coding RNAs (LncRNAs) constitute a wide and extremely diverse family of RNA transcripts that are greater than 200 base pairs in length and are not translated into proteins. X-inactive specific transcript (XIST) was the first long non-coding RNA to be discovered, back in 1991. Its function in X-chromosome inactivation has been extensively studied for three decades, though other functional roles of XIST that involve a variety of fascinating mechanisms remain to be elucidated. Here, we review the emerging oncogenic role of XIST in various human cancers.

Key Words: X chromosome inactivation, XIST, LncRNA, CeRNA, Human cancer; miRNA

\section{INTRODUCTION}

The specific transcript involved in X chromosome inactivation is called $\mathrm{X}$-inactive specific transcript (XIST), and it was the first long non-coding RNA to be identified, by Brown et al. in 1991. XIST is thought to be a critical determinant for $\mathrm{X}$ chromosome inactivation. It is a $17,000-$ base-pair long non-coding RNA (IncRNA) that is spliced, polyadenylated, and constrained to the nucleus, and it does not produce a protein product.

A recent round of studies has provided new evidence of an oncogenic role of XIST in several cancers (Fig. 1). XIST has been shown to be highly expressed in tumor tissues compared to normal tissues. Furthermore, many reports have underlined its clinical significance and suggested that XIST can serve as a prognostic marker for many tumors. Mechanistically, XIST exerts its oncogenic effects by acting mainly as a competing endogenous RNA (ceRNA); the mechanism of ceRNAs is a relatively new epigenetic concept, which suggests that a competition might exist between a microRNA (miRNA) and a lncRNA leading to the upregulation of a target gene (Thomson and Dinger, 2016). In fact, XIST seems to act as a sponge for a plethora of miRNAs in various tumors. As the ceRNA concept provides new insights and indicates a more sophisticated post-transcriptional gene regulation role of XIST, via miRNA sequestration, deciphering the newly emerging function of XIST is needed now more than ever.

This review provides an overview of the auspicious sponge role of XIST in cancer, as summarized in Table 1.

\section{Lung cancer}

Recent studies have consolidated previous findings establishing a correlation between the XIST IncRNA and lung cancer, where XIST has been proven to be very important

Received: March 8, 2019 / Accepted: June 14, 2019

* Graduate student, ${ }^{* *}$ Professor.

${ }^{\dagger}$ Corresponding author: Myoung Hee Kim. Department of Anatomy, Embryology Laboratory, and Brain Korea 21 PLUS Project for Medical Science, Yonsei University College of Medicine, Seoul 03722, Korea.

Tel: +82-2-2228-1647, Fax: +82-2-365-0700, e-mail: mhkim1@yuhs.ac

(C) The Korean Society for Biomedical Laboratory Sciences. All rights reserved.

(c) This is an Open Access article distributed under the terms of the Creative Commons Attribution Non-Commercial License (http://creativecommons.org/licenses/by-nc/3.0/) which permits unrestricted non-commercial use, distribution, and reproduction in any medium, provided the original work is properly cited. 
Table 1. Functional characterization of XIST in human cancers

\begin{tabular}{|c|c|c|c|c|c|c|}
\hline Cancer type & $\begin{array}{c}\text { XIST } \\
\text { expression } \\
\text { level }\end{array}$ & $\begin{array}{l}\text { XIST molecular } \\
\text { target (s) }\end{array}$ & $\begin{array}{l}\text { Downstream } \\
\text { genes }\end{array}$ & $\begin{array}{l}\text { Effect on cancer } \\
\text { progression and } \\
\text { metastasis }\end{array}$ & $\begin{array}{l}\text { Functional role of } \\
\text { XIST (oncogene/ } \\
\text { tumor suppressor) }\end{array}$ & References \\
\hline \multirow{9}{*}{$\begin{array}{l}\text { Non-small-cell } \\
\text { lung cancer }\end{array}$} & Upregulated & $\begin{array}{l}\mathrm{miR}-367 \text { and } \\
\mathrm{miR}-141\end{array}$ & ZEB2 & $\begin{array}{l}\uparrow \text { TGF- } \beta \text { induced } \\
\text { EMT }\end{array}$ & Oncogene & Li et al., 2018 \\
\hline & Upregulated & miR-137 & PXN/Notch-1 & $\begin{array}{l}\uparrow \text { Proliferation } \\
\uparrow \text { Invasion }\end{array}$ & Oncogene & $\begin{array}{l}\text { Jiang et al., } 2018 \\
\text { Wang et al., } 2018\end{array}$ \\
\hline & Upregulated & miR-186-5p & Unknown & $\begin{array}{l}\uparrow \text { Cell viability } \\
\uparrow \text { Invasion } \\
\downarrow \text { Apoptosis }\end{array}$ & Oncogene & Wang et al., 2017a \\
\hline & Upregulated & miR-449a & Bcl-2 & $\begin{array}{l}\uparrow \text { Cell proliferation } \\
\uparrow \text { Cell migration and } \\
\text { invasion } \\
\downarrow \text { Apoptosis }\end{array}$ & Oncogene & Zhang et al., 2017 \\
\hline & Upregulated & miR-374a & LARP1 & $\begin{array}{l}\text { † Cell growth } \\
\uparrow \text { Migration } \\
\uparrow \text { Invasion } \\
\uparrow \text { Tumorigenicity }\end{array}$ & Oncogene & Xu et al., 2017b \\
\hline & Upregulated & $\mathrm{EZH} 2$ & KLF2 & $\begin{array}{l}\text { † Cell proliferation } \\
\text { † Migration } \\
\uparrow \text { Invasion } \\
\text { † Tumorigenicity } \\
\text { Poor prognosis }\end{array}$ & Oncogene & Fang et al., 2016 \\
\hline & Upregulated & miR-17 & ATG7 & $\begin{array}{l}\uparrow \text { Autophagy } \\
\uparrow \text { TNM stage } \\
\uparrow \text { Chemoresistance }\end{array}$ & Oncogene & Sun et al., 2017b \\
\hline & Upregulated & Let-7i & BAG-1 & $\begin{array}{l}\text { Resistance to } \\
\text { cisplatin }\end{array}$ & Oncogene & Sun et al., 2017a \\
\hline & Upregulated & miR-140 & iASPP & $\begin{array}{l}\uparrow \text { Cell proliferation } \\
\downarrow \text { Apoptosis } \\
\uparrow \text { Metastasis }\end{array}$ & Oncogene & Tang et al., 2017 \\
\hline \multirow{8}{*}{$\begin{array}{l}\text { Colorectal and } \\
\text { Gastric cancer }\end{array}$} & Upregulated & miR-185 & TGF- $\beta 1$ & $\begin{array}{l}\uparrow \text { Cell growth } \\
\uparrow \text { GC progression }\end{array}$ & Oncogene & Zhang et al., 2018 \\
\hline & Upregulated & miR-34a & $\begin{array}{l}\text { WNT1/ } \\
\beta \text {-catenin }\end{array}$ & $\begin{array}{l}\uparrow \text { Cell proliferation } \\
\uparrow \text { Invasion }\end{array}$ & Oncogene & Sun et al., 2018a \\
\hline & Upregulated & miR-137 & $\mathrm{EZH} 2$ & $\begin{array}{l}\uparrow \mathrm{EMT} \\
\uparrow \text { Invasion }\end{array}$ & Oncogene & Liu et al., 2018a \\
\hline & Upregulated & miR-497 & MACC1 & $\begin{array}{l}\uparrow \text { Cell cycle } \\
\text { progression } \\
\text { † Invasion }\end{array}$ & Oncogene & Ma et al., 2017b \\
\hline & Upregulated & $\operatorname{miR}-200 b-3 p$ & ZEB1 & $\begin{array}{l}\text { † Cell proliferation } \\
\uparrow \text { Invasion } \\
\uparrow \text { EMT } \\
\uparrow \text { Stemness } \\
\downarrow \text { Overall survival }\end{array}$ & Oncogene & Chen et al., 2017 \\
\hline & Upregulated & miR-132-3p & MAPK1 & $\begin{array}{l}\uparrow \text { Cell cycle } \\
\text { progression }\end{array}$ & Oncogene & Song et al., 2017 \\
\hline & Upregulated & Unknown & $\mathrm{TS}$ & $\begin{array}{l}\downarrow \text { 5-FU cytotoxicity } \\
\text { Poor therapeutic } \\
\text { efficacy }\end{array}$ & Oncogene & Xiao et al., 2017 \\
\hline & Upregulation & miR-101 & $\mathrm{EZH} 2$ & $\begin{array}{l}\uparrow \text { Tumor } \\
\text { aggressiveness } \\
\text { Poor patient survival }\end{array}$ & Oncogene & Chen et al., 2016 \\
\hline
\end{tabular}


Table 1. Functional characterization of XIST in human cancers (Continued)

\begin{tabular}{|c|c|c|c|c|c|c|}
\hline Cancer type & $\begin{array}{c}\text { XIST } \\
\text { expression } \\
\text { level }\end{array}$ & $\begin{array}{l}\text { XIST molecular } \\
\text { target (s) }\end{array}$ & $\begin{array}{l}\text { Downstream } \\
\text { genes }\end{array}$ & $\begin{array}{l}\text { Effect on cancer } \\
\text { progression and } \\
\text { metastasis }\end{array}$ & $\begin{array}{l}\text { Functional role of } \\
\text { XIST (oncogene/ } \\
\text { tumor suppressor) }\end{array}$ & References \\
\hline \multirow{4}{*}{$\begin{array}{l}\text { Hepatic } \\
\text { cancer }\end{array}$} & Upregulated & miR-194-5p & MAPK1 & $\begin{array}{l}\uparrow \text { Cell proliferation } \\
\boldsymbol{\uparrow} \text { Migrasion } \\
\boldsymbol{\uparrow} \text { Invation }\end{array}$ & Oncogene & Kong et al., 2018 \\
\hline & Downregulated & miR-181a & PTEN & $\begin{array}{l}\downarrow \text { Cell proliferation } \\
\downarrow \text { Invasion }\end{array}$ & Tumor suppressor & Chang et al., 2017 \\
\hline & Upregulated & miR-139-5p & PDK1 & $\begin{array}{l}\uparrow \text { Cell cycle } \\
\text { progression } \\
\downarrow \text { Apoptosis }\end{array}$ & Oncogene & Mo et al., 2017 \\
\hline & Downregulated & miR-92b & Smad7 & $\begin{array}{l}\downarrow \text { Cell proliferation } \\
\downarrow \text { Metastasis }\end{array}$ & Tumor suppressor & Zhuang et al., 2016 \\
\hline \multirow[t]{2}{*}{$\begin{array}{l}\text { Breast } \\
\text { cancer }\end{array}$} & Downregulated & miR-155 & $\mathrm{CDX} 1$ & $\begin{array}{l}\downarrow \text { Cell growth } \\
\downarrow \text { Migration } \\
\downarrow \text { Invasion }\end{array}$ & Tumor suppressor & Zheng et al., 2018 \\
\hline & Downregulated & PHLPP1 & $\mathrm{AKT}$ & $\downarrow$ Cell viability & Tumor suppressor & Huang et al., 2016 \\
\hline \multirow{5}{*}{ Glioma } & Upregulated & miR-137 & Rac1 & $\begin{array}{l}\uparrow \text { Cell proliferation } \\
\uparrow \text { Tumorigenesis }\end{array}$ & Oncogene & Wang et al., 2017b \\
\hline & Upregulated & $\operatorname{miR}-29 c$ & $\begin{array}{l}\text { MSH6/SP1/ } \\
\text { MGMT }\end{array}$ & $\begin{array}{l}\text { 1 Chemoresistance to } \\
\text { TMZ }\end{array}$ & Oncogene & Du et al., 2017 \\
\hline & Upregulated & miR-137 & FOXC1/ZO-2 & $\begin{array}{l}\uparrow \text { Angiogenesis } \\
\downarrow \text { Blood-tumor } \\
\text { permeability }\end{array}$ & Oncogene & Yu et al., 2017 \\
\hline & Upregulated & $\operatorname{miR}-429$ & Unknown & $\begin{array}{l}\text { T Tumorigenicity } \\
\text { † Angiogenesis } \\
\uparrow \text { Metastasis }\end{array}$ & Oncogene & Cheng et al., 2017 \\
\hline & Upregulated & miR-152 & KLF4 & $\begin{array}{l}\uparrow \text { Cell proliferation } \\
\uparrow \text { Migration } \\
\uparrow \text { Invasion } \\
\downarrow \text { Stemness }\end{array}$ & Oncogene & Yao et al., 2015 \\
\hline \multirow{3}{*}{$\begin{array}{l}\text { Pancreatic } \\
\text { cancer }\end{array}$} & Upregulated & miR-34a-5p & Unknown & $\begin{array}{l}\uparrow \text { Cell proliferation } \\
\uparrow \text { Migration } \\
\uparrow \text { Invasion } \\
\downarrow \text { Apoptosis }\end{array}$ & Oncogene & Sun et al., 2018a \\
\hline & Upregulated & miR-133a & EGFR & $\begin{array}{l}\uparrow \text { Cell proliferation } \\
\downarrow \text { Poor prognosis }\end{array}$ & Oncogene & Wei et al., 2017 \\
\hline & Upregulated & $\begin{array}{l}\text { miR-140/ } \\
\text { miR-124 }\end{array}$ & iASPP & $\begin{array}{l}\text { † Cell cycle } \\
\text { progression } \\
\uparrow \text { Cell proliferation } \\
\text { Poor } \\
\text { clinicopathological } \\
\text { features }\end{array}$ & Oncogene & Liang et al., 2017 \\
\hline \multirow{2}{*}{$\begin{array}{l}\text { Bladder } \\
\text { cancer }\end{array}$} & Upregulated & miR-200c & Unknown & $\begin{array}{l}\uparrow \text { Cancer stem cells } \\
\text { clonality and } \\
\text { self-renewal } \\
\text { EMT }\end{array}$ & Oncogene & Xu et al., 2018 \\
\hline & Upregulated & $\operatorname{miR}-124$ & $\mathrm{AR}$ & $\begin{array}{l}\uparrow \text { Cell proliferation } \\
\uparrow \text { Invasion } \\
\uparrow \text { Migration }\end{array}$ & Oncogene & Xiong et al., 2017 \\
\hline
\end{tabular}


Table 1. Functional characterization of XIST in human cancers (Continued)

\begin{tabular}{|c|c|c|c|c|c|c|}
\hline Cancer type & $\begin{array}{c}\text { XIST } \\
\text { expression } \\
\text { level }\end{array}$ & $\begin{array}{l}\text { XIST molecular } \\
\text { target (s) }\end{array}$ & $\begin{array}{l}\text { Downstream } \\
\text { genes }\end{array}$ & $\begin{array}{l}\text { Effect on cancer } \\
\text { progression and } \\
\text { metastasis }\end{array}$ & $\begin{array}{l}\text { Functional role of } \\
\text { XIST (oncogene/ } \\
\text { tumor suppressor) }\end{array}$ & References \\
\hline $\begin{array}{l}\text { Bladder } \\
\text { cancer }\end{array}$ & Upregulated & miR-139-5p & Wnt1 & $\begin{array}{l}\uparrow \text { Cell growth } \\
\uparrow \text { Metastasis } \\
\text { Worse patient } \\
\text { survival }\end{array}$ & Oncogene & Hu et al., 2017 \\
\hline $\begin{array}{l}\text { Cervical } \\
\text { cancer }\end{array}$ & Upregulated & miR-200a & Fus & $\begin{array}{l}\text { T Tumor progression } \\
\text { † Distant metastasis } \\
\text { † Tumor size } \\
\text { † FIGO stage }\end{array}$ & Oncogene & Zhu et al., 2018 \\
\hline \multirow{4}{*}{ Osteosarcoma } & Upregulated & miR-195-5p & YAP & $\begin{array}{l}\text { † Cell proliferation } \\
\mathbf{\uparrow} \text { Invasion } \\
\mathbf{\uparrow} \text { EMT } \\
\mathbf{\uparrow} \text { Tumor growth } \\
\text { Poor clinical prognosis }\end{array}$ & Oncogene & Yang et al., 2018 \\
\hline & Upregulated & miR-320b & RAP2B & $\begin{array}{l}\uparrow \text { Cell proliferation } \\
\uparrow \text { Invasion }\end{array}$ & Oncogene & Lv et al., 2018 \\
\hline & Downregulated & $\operatorname{miR}-21-5 p$ & PDCD4 & $\begin{array}{l}\downarrow \text { Cell proliferation } \\
\downarrow \text { EMT } \\
\downarrow \text { Invasion } \\
\downarrow \text { Overall survival }\end{array}$ & Tumor suppressor & $\begin{array}{l}\text { Zhang and Xia, } \\
2017\end{array}$ \\
\hline & Upregulated & EZH2 & $\mathrm{P} 21$ & $\begin{array}{l}\uparrow \text { Cell proliferation } \\
\uparrow \text { Cell cycle }\end{array}$ & Oncogene & Xu et al., 2017a \\
\hline \multirow{3}{*}{$\begin{array}{l}\text { Nasopharynx } \\
\text { cancer }\end{array}$} & Upregulated & miR-491-5p & Notch3 & $\begin{array}{l}\uparrow \text { Cell proliferation } \\
\uparrow \text { Invasion } \\
\uparrow \text { Tumor growth } \\
\downarrow \text { Apoptosis }\end{array}$ & Oncogene & Cheng et al., 2018 \\
\hline & Upregulated & $\operatorname{miR}-29 c$ & Unknown & $\begin{array}{l}\text { † Cell proliferation } \\
\uparrow \text { Radioresistance }\end{array}$ & Oncogene & Han et al., 2017 \\
\hline & Upregulated & $\operatorname{miR}-34 a-5 p$ & $\mathrm{E} 2 \mathrm{~F} 3$ & $\begin{array}{l}1 \text { Cell growth } \\
\text { Poor patient survival }\end{array}$ & Oncogene & Song et al., 2016 \\
\hline
\end{tabular}

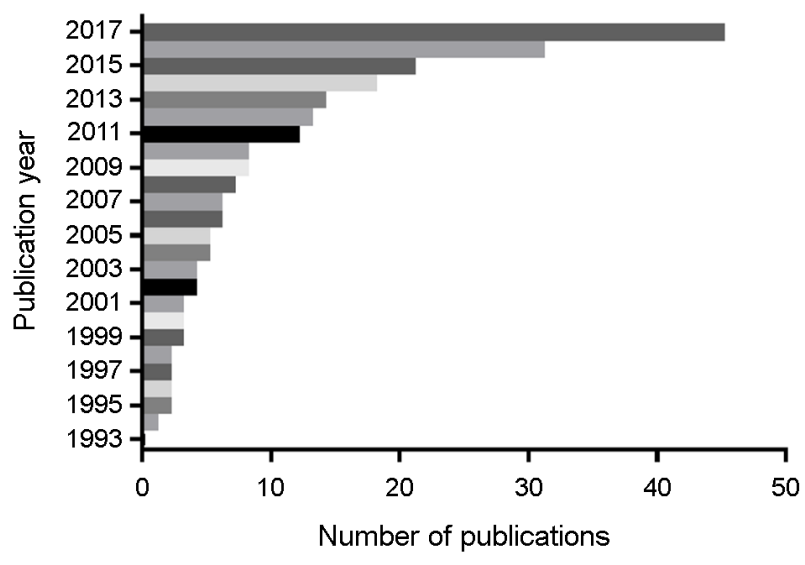

Fig. 1. Change in the number of publications describing the cancerassociated role of XIST. Online analysis from the National Library of Medicine PubMed search using the terms "XIST" and "cancer" (from Jan. 1 to Dec. 31 as date limitations). in lung carcinogenesis because it was reported to act as a ceRNA on various miRNAs. For instance, in non-small cell lung carcinoma (NSCLC), a thorough analysis of XIST expression revealed that XIST is overexpressed in nonsmall cell lung cancer tissues compared to normal tissues. In addition, the high expression of XIST in lung cancer tissues and cell lines has been associated with more advanced cancer stages and a worse prognosis. Currently, many studies point to an essential role of XIST in promoting epithelialmesenchymal transition (EMT), as reported by (Li et al., 2018). In their study, XIST knockdown was sufficient to inhibit ZEB2 expression and to abrogate the TGF- $\beta 1$-induced EMT in NSCLC, which translates into pulmonary metastasis inhibition in mice mainly by sponging both miR-367 and 
miR-141. In support of these findings, Jiang et al. (2018) have shown that XIST overexpression promotes NSCLC invasion by sponging miR-137 in vitro and promotes tumor growth in vivo as a result of PXN upregulation, a focal adhesion-associated protein that boosts cell migration and mobility. Consistently, the knockdown of XIST suppresses cell proliferation and TGF- $\beta 1$-induced EMT in NSCLC by sponging miR-137, which induces an aberrant activation of Notch (Wang et al., 2018). In line with the above findings, the modulation of miR-186-5p by XIST boosts lung cancer cell proliferation and invasion (Wang et al., 2017a). On the other hand, Zhang et al. (2017) successfully identified that XIST is a negative regulator of Bcl-2 through reciprocal repression between it and miR-449a. Moreover, a trend for the increased oncogenic expression of XIST has been observed in NSCLC. Consequently, Xu et al. (2017b) showed that the expression of miR-374a was abolished by XIST acting as ceRNA, which was found to be the reason for the upregulation of LARP1, an RNA-binding protein that controls the 5'-terminal oligopyrimidine tract (TOP) mRNA translation as a key regulator of the mTOR pathway. In addition, XIST has been shown to be involved in the epigenetic regulation in NSCLC by interacting with histone modifier such as Enhancer of zeste homolog 2 (EZH2) to suppress the transcription of the KLF2 gene by enhancing its binding to the KLF2 promoter (Fang et al., 2016). Notably, the strong involvement of XIST in autophagy has been demonstrated by Sun et al. (2017b), as XIST knockdown sensitized NSCLC cells to chemotherapy by upregulating miR-17, which targets the 3'-untranslated region of ATG7. Concomitantly, the lncRNA XIST bolsters the resistance of human lung adenocarcinoma cells to cisplatin by functioning as a ceRNA to suppress let-7i, which promotes its downstream target BAG-1, an anti-apoptotic protein shown to interact with BCL-2 (Sun et al., 2017a). In agreement with the above findings, XIST targets miR-140, which blocks iASPP oncogene expression in human lung cancer (Tang et al., 2017).

\section{Colorectal and Gastric cancer}

Several recently published studies have examined the alterations affecting XIST in colon cancer. Notably, the interaction of XIST with several miRNAs has been emphasized in colorectal and gastric cancer. For instance, XIST has been reported to be a miR-185 sponge that regulates TGF- $\beta 1$. Hence, XIST seems to play an oncogenic role in gastric cancer as demonstrated by Zhang et al. (2018). Moreover, according to a study conducted by Sun et al. (2018a), XIST sponged miRNA-34a. The endogenous suppressive effect of XIST promoted the proliferation and invasion of colon cancer cells by $\mathrm{Wnt} / \beta$-catenin signaling activation, which leads to the upregulation of c-Myc and cyclin D1 (Sun et al., 2018b). On the other hand, XIST has been shown to boost EZH2 by targeting the miR-137-EZH2 axis to foster the tumor metastasis of colorectal cancer cells (Liu et al., 2018a). Consistent with these results, the lncRNA XIST has been proposed as a novel predictive marker for patients with digestive system tumors, as the high expression of XIST was linked with unfavorable overall survival and a poor prognosis (Liu et al., 2018b). In addition, Ma et al. (2017b) have highlighted the cell cycle regulatory role of XIST in gastric cancer where it promotes G1-S cell cycle progression, which has an anti-apoptotic effect and a growth-boosting effect. This effect is mediated through sponging the miR-497 that suppress its downstream target, metastasis-associated in colon cancer 1 (MACC1). Other evidence published by Chen et al. supports previous findings that stipulate that the long non-coding RNA XIST regulates EMT and metastasis in colorectal cancer, as the knockdown of XIST significantly upregulated the expression of miR-200b-3p that targets Ebox-binding homeobox 1 (ZEB1), which has a contributing role in metastasis and cancer invasiveness (Chen et al., 2017). These findings are concordant with those of Song et al. (2017) that stipulate that miR-132-3p is sponged by XIST, which is a direct target of Mitogen-Activated Protein Kinase 1 (MAPK1), which promotes colorectal cancer (CRC) survival and proliferation. It should be noted that XIST promotes resistance to chemoresistance drugs such as 5-fluorouracil (5-FU) in colorectal cancer by promoting thymidylate synthase, a crucial enzyme in the early stages of DNA synthesis and a direct target of 5-FU (Xiao et al., 2017). It was also revealed by Chen et al. (2016) that XIST modulates EZH2 expression by sponging miR-101, a negative regulator of EZH2. 


\section{Liver cancer}

In contrast to what has been observed in lung cancer and gastric cancer, in which the lncRNA XIST serves as an oncogene, the findings on XIST and liver cancer are seemingly conflicting. Hence, additional studies are urgently needed to reconcile these conflicting findings. For instance, Kong et al. (2018) have shown that the aberrant overexpression of XIST in hepatocellular carcinoma cells promoted the proliferation and invasion of liver cancer cells, where XIST might act as a sponge of miR-194-5p, which derepresses MAPK1. However, Chang et al. (2017) reported that the induced overexpression of XIST in hepatocellular carcinoma (HCC) cells abrogates invasion, migration, and proliferation compared to those in control cells. This effect is facilitated through the XIST-mediated epigenetic regulation of miR181a, a well-known inhibitor of phosphatase and tensin homolog (PTEN). In keeping with this previous finding, Mo et al. (2017) have found a negative correlation between XIST and miR-139-5p and revealed that the reciprocal inhibition between miR-139-5p and XIST promoted pyruvate dehydrogenase kinase 1 (PDK1), a direct target of miR139-5p and an AKT activator at T308 residue. Consistent with the findings of the Mo et al. (2017) and Ma et al. (2017a) reported that XIST and its activator JPX lncRNA were downregulated in patients with HCC and that JPX/ XIST upregulation in patients with hepatocellular carcinoma is associated with a good prognosis. In addition, Zhuang et al. (2016) have just confirmed the aforementioned findings by claiming that miR-92b, a microRNA with an oncogenic role in hepatocellular carcinoma, is targeted by XIST, thus hampering the miR-92a inhibiting effect on Smad7, a TGF- $\beta$ type 1 receptor antagonist with a tumor suppressor role.

\section{Breast cancer}

Zheng et al. (2018) have shown that XIST is a cell growth and metastasis inhibitor in breast cancer. This role seems irrevocably linked to its sponge activity of miR-155, which directly targets CDX1, an inducer of genes related to cell adhesions in angiogenesis and EMT. Of particular interest, a study conducted by Huang et al. (2016) showed that a significant XIST reduction in breast tumor samples and breast cancer cell lines was associated with JPX downregulation and aberrant AKT activation. Moreover, XIST knockdown diminished PHLPP1 expression, which plays an AKT phosphatase role. On the other hand, as the development of resistance to chemotherapy remains an issue in breast cancer as well as many other cancers, Schouten et al. (2016) investigated the impact of XIST and tumor suppressor p53-binding protein 1 (53BP1) expression on recurrence-free survival, disease-free survival, and overall survival in patients with breast cancer carrying the BRCA1 mutation and showed that low 53BP1 and high XIST expression are linked to a poor outcome following high-dose alkylating chemotherapy.

\section{Glioma}

Recently published data provide evidence of the oncogenic role of XIST in human glioma, whereby XIST has oncogenic activity by targeting miR-137, based on the findings of Wang et al. (2017b). Indeed, XIST, by sponging miR137, enhanced Rac1 expression, a pleiotropic regulator of many cellular processes such as the cell cycle, differentiation, invasion, and motility. Notably, in the case of high-grade glioma whereby the use of a combination of chemotherapy and radiotherapy results in a clear improvement, although it remains limited because of recurrence, XIST has been shown to boost the chemoresistance of glioma cells to temozolomide (TMZ) by direct binding to miR-29c. This was confirmed by knockdown of XIST, which significantly increased miR-29c expression but suppressed the expression of MGMT, SP1, and MSH6, which are considered important DNA mismatch repair (MMR) regulators (Du et al., 2017). On the other hand, a causal relationship between XIST expression and glioma angiogenesis and blood-tumor barrier permeability has been established by Yu et al. (2017), who demonstrated that miR-137 is a direct target of XIST, which inhibits FOXC1 and tight junction protein $\mathrm{ZO}-2$ in normal cells. Hence, XIST knockdown facilitates the delivery of chemotherapeutic agents through the blood-tumor barrier and abrogates angiogenesis by reducing the promoter activity of CXCR7. Alternatively, the sponging effect exerted by XIST on miR429 has been proposed by Cheng et al. (2017) as a promoter of glioma angiogenesis and tumorigenicity. In line with the above findings, Yao et al. (2015) have elucidated the cor- 
relation between XIST expression and human glioblastoma stem cells by demonstrating the existence of reciprocal repression between miR-152 and XIST, which bind to each other. Indeed, XIST knockdown promoted the expression of miR-152, which triggered apoptosis and hindered glioma stem cell proliferation, migration, and invasion as well.

\section{Pancreas cancer}

Current studies on XIST and pancreas cancer have unanimously agreed that XIST exerts an oncogenic function in pancreatic cancer. It is believed that the knockdown of XIST in pancreatic cancer cells induces apoptosis, reduces proliferation, and inhibits migration and invasion, as supported by the findings of Sun et al. (2018a) whereby the complementary base pairing between XIST and miR-34a-5p, a well-known tumor suppressor, hampered its expression. Therefore, promotes pancreatic cancer progression. In support of this conclusion, Wei et al. (2017) investigated the correlation between XIST and miR 133a and found out that XIST negatively regulated miR-133a and that miR-133a downregulation imposed by XIST boosted EGFR expression as a result of liberating the EGFR 3'-UTR micro-RNA response elements. Moreover, XIST has been reported to act as a promoter of human pancreatic carcinoma by targeting miR-140 and miR-124m, which both target endogenous iASPP and CDK1, two important anti-apoptotic proteins (Liang et al., 2017).

\section{Bladder cancer}

Current studies on lncRNA XIST suggest that XIST has an oncogenic role in bladder cancer. While several reports have demonstrated the overexpression of XIST in human bladder tissues, which correlated with a poor prognosis, a recent study by Xu et al. (2018) points to a link between XIST expression and stemness, as the knockdown of XIST in bladder cancer cells dramatically abrogated self-renewal and clone formation efficiency. This effect seems to be mediated through inhibiting miR-200c which is a tumor suppressor that suppresses growth and EMT in bladder carcinoma (Xu et al., 2018). In keeping with these findings, Xiong et al. (2017) have confirmed the interaction between XIST and miR-124. Mechanistically, the interaction between XIST and miR-124 abrogated the binding capability of miR-124 to the androgen receptor (AR) 3'-UTR region and thus promoted AR expression, which boosts bladder cancer progression. In conjunction with previous findings, Hu et al. (2017) provided support for the XIST lncRNA sponge hypothesis, as they concluded that XIST knockdown substantially inhibited bladder cancer growth and metastatic potential in vitro and tumor size in vivo considering that miR-139-5p targets Wnt1, a proto-oncogene implicated in oncogenesis, embryogenesis, and cell fate determination.

\section{Cervical cancer}

In cervical after cancer, the increased expression of XIST has been associated with a better overall survival (OS) in patients with cervical squamous cell carcinoma receiving chemoradiation therapy, as the 4-year overall survival rate was $87.1 \%$ in patients highly expressing XIST as opposed to $54.4 \%$ in patients with low XIST expression as reported by Kobayashi et al. (2016). In an attempt to investigate the sponge function of XIST in cervical cancer, Zhu et al. (2018) carried out a loss-of-function assay to determine which miRNA is the interaction partner of XIST. Interestingly, miR200 was inhibited by XIST, which induced the upregulation of RNA-binding protein Fused in Sarcoma/Translocated in Sarcoma (FUS/TLS), an important oncogenic protein.

\section{Osteosarcoma}

There is an urgent need to unravel the function of XIST in osteosarcoma. Yang et al. (2018) examined the hypothesis that XIST is a miRNA sponging lncRNA in osteogenic sarcoma by analyzing the interaction of XIST with its downstream target miR-195-5p using dual-luciferase assays and bioinformatics prediction tools. Importantly, XIST was found to be a direct inhibitor of miR-195p, which decreased the binding between the YAP 3'-UTR and miR-195-5p. Hence, the YAP promoter was activated, boosting YAP expression in osteosarcoma cells. Another study conducted by Li et al. (2017) highlighted that XIST overexpression in osteosarcoma has a correlation with advanced tumor size, advanced clinical stage, distant metastasis progression, and thus a poor prognosis in patients with osteosarcoma. Additionally, XIST overexpression promoted osteosarcoma cell proliferation. 
In parallel, another interesting finding by Lv et al. (2018) suggested that XIST targeted miR-320b, thus promoting osteosarcoma proliferation and invasion by upregulating rasrelated protein RAP2B. On the contrary, XIST has been reported by Zhang and Xia (2017) to play a tumor suppressor role in osteosarcoma by endogenously competing with miR-21-5p, thus upregulating PDCD4, an apoptosisinducing protein. On another note, Xu et al. (2017a) have reported that XIST overexpression in OS tissues impedes p21 expression epigenetically. This is mediated by XIST binding to $\mathrm{EZH} 2$, the main member of the PRC2 complex.

\section{Nasopharyngeal cancer}

As detailed in this review, many studies have shown that XIST is an endogenous competitor of several tumor suppressor miRNAs in various tumors, which promotes tumor proliferation, resistance, and metastasis. Nasopharyngeal carcinoma is no exception, as the knockdown of XIST mitigated nasopharyngeal carcinoma advancement by upregulating miR-491-5p, which suppressed Notch3 expression in nasopharyngeal carcinoma cells (Cheng et al., 2018). Moreover, Han et al. (2017) elucidated that miR-29c downregulation by XIST enhanced the radioresistance of nasopharyngeal carcinoma cells, thus demonstrating that the XIST/miR-29c axis might be promising for overcoming nasopharyngeal carcinoma resistance to radiotherapy. Song et al. (2016) clarified the oncogenic function of XIST in nasopharyngeal carcinoma by showing the involvement of XIST in upregulating E2F3 through miR-34a-5p sponging.

\section{CONCLUSION}

As it has been almost three decades since the discovery of XIST, the oncogenic role of XIST is systematically being clarified. There is a substantive evidence pertaining to the oncogenic overexpression of XIST across several tumor tissues in conjunction with its ceRNA function, which involves a plethora of miRNA targets that differ in a tissueand context-dependent manner. Within this framework, significant progress has been achieved in identifying the interacting partners of XIST miRNA in vitro and in vivo. However, further studies in other cancer types such as leukemia are urgently needed, and several questions that are essential to understand the oncogenic functions of XIST remain unanswered, and thus could open new research avenues.

\section{ACKNOWLEDGMENT}

This research was supported by the Basic Science Research Program of the National Research Foundation funded by the Ministry of Education, Science, and Technology, Korea (NRF- 2016R1A2B2011821).

\section{CONFLICTS OF INTEREST}

No potential conflict of interest relevant to this article was reported.

\section{REFERENCES}

Brown CJ, Ballabio A, Rupert JL, Lafreniere RG, Grompe M, Tonlorenzi R, Tonlorenzi R, Willard HF. Agene from the region of the human $\mathrm{X}$ inactivation centre is expressed exclusively from the inactive X chromosome. Nature. 1991. 349: 38-44.

Chang S, Chen B, Wang X, Wu K, Sun Y. Long non-coding RNA XIST regulates PTEN expression by sponging miR-181a and promotes hepatocellular carcinoma progression. BMC Cancer. 2017. 17: 248.

Chen DL, Chen LZ, Lu YX, Zhang DS, Zeng ZL, Pan ZZ, Huang P, Wang FH, Li YH, Ju HQ, Xu RH. Long noncoding RNA XIST expedites metastasis and modulates epithelial-mesenchymal transition in colorectal cancer. Cell Death Dis. 2017. 8: e3011.

Chen DL, Ju HQ, Lu YX, Chen LZ, Zeng ZL, Zhang DS, Luo HY, Wang F, Qiu MZ, Wang DS, Xu DZ, Zhou ZW, Pelicano H, Huang P, Xie D, Wang FH, Li YH, Xu RH. Long non-coding RNA XIST regulates gastric cancer progression by acting as a molecular sponge of miR-101 to modulate EZH2 expression. J Exp Clin Cancer Res. 2016. 35: 142.

Cheng Q, Xu X, Jiang H, Xu L, Li Q. Knockdown of long noncoding RNA XIST suppresses nasopharyngeal carcinoma progression by activating miR-491-5p. J Cell Biochem. 2018. 119: 3936-3944.

Cheng Z, Li Z, Ma K, Li X, Tian N, Duan J, Xiao X, Wang Y. Long non-coding RNA XIST promotes glioma tumorigenicity and angiogenesis by acting as a molecular sponge of miR-429. J Cancer. 2017. 8: 4106-4116.

Du P, Zhao H, Peng R, Liu Q, Yuan J, Peng G, Liao Y. LncRNA- 
XIST interacts with miR-29c to modulate the chemoresistance of glioma cell to TMZ through DNA mismatch repair pathway. Biosci Rep. 2017. 37: bsr20170696.

Fang J, Sun CC, Gong C. Long noncoding RNA XIST acts as an oncogene in non-small cell lung cancer by epigenetically repressing KLF2 expression. Biochem Biophys Res Commun. 2016. 478: 811-817.

Han Q, Li L, Liang H, Li Y, Xie J, Wang Z. Downregulation of lncRNA $X$ inactive specific transcript (XIST) suppresses cell proliferation and enhances radiosensitivity by upregulating mir-29c in nasopharyngeal carcinoma cells. Med Sci Monit. 2017. 23: 4798-4807.

Huang YS, Chang CC, Lee SS, Jou YS, Shih HM. Xist reduction in breast cancer upregulates AKT phosphorylation via HDAC3mediated repression of PHLPP1 expression. Oncotarget. 2016. 7: 43256-43266.

Hu Y, Deng C, Zhang H, Zhang J, Peng B, Hu C. Long non-coding RNA XIST promotes cell growth and metastasis through regulating miR-139-5p mediated Wnt/beta-catenin signaling pathway in bladder cancer. Oncotarget. 2017. 8: 94554-94568.

Jiang H, Zhang H, Hu X, Li W. Knockdown of long non-coding RNA XIST inhibits cell viability and invasion by regulating miR-137/PXN axis in non-small cell lung cancer. Int J Biol Macromol. 2018. 111: 623-631.

Kobayashi R, Miyagawa R, Yamashita H, Morikawa T, Okuma K, Fukayama M, Ohtomo K, Nakagawa K. Increased expression of long non-coding RNA XIST predicts favorable prognosis of cervical squamous cell carcinoma subsequent to definitive chemoradiation therapy. Oncol Lett. 2016.12: 3066-3074.

Kong Q, Zhang S, Liang C, Zhang Y, Kong Q, Chen S, Qin J, Jin Y. LncRNA XIST functions as a molecular sponge of miR-194$5 p$ to regulate MAPK1 expression in hepatocellular carcinoma cell. J Cell Biochem. 2018. 119: 4458-4468.

Liang S, Gong X, Zhang G, Huang G, Lu Y, Li Y. The lncRNA XIST interacts with miR-140/miR-124/iASPP axis to promote pancreatic carcinoma growth. Oncotarget. 2017. 8: 113701 $-113718$.

Li GL, Wu YX, Li YM, Li J. High expression of long non-coding RNA XIST in osteosarcoma is associated with cell proliferation and poor prognosis. Eur Rev Med Pharmacol Sci. 2017. 21: 2829-2834.

Li C, Wan L, Liu Z, Xu G, Wang S, Su Z, Zhang Y, Zhang C, Liu $X$, Lei Z, Zhang HT. Long non-coding RNA XIST promotes TGF-beta-induced epithelial-mesenchymal transition by regulating miR-367/141-ZEB2 axis in non-small-cell lung cancer.
Cancer Lett. 2018. 418: 185-195.

Liu X, Cui L, Hua D. Long non-coding RNA XIST regulates miR-137-EZH2 axis to promote tumor metastasis in colorectal cancer. Oncol Res. 2018a. 27: 99-105.

Liu X, Ming X, Jing W, Luo P, Li N, Zhu M, Yu M, Liang C, Tu J. Long non-coding RNA XIST predicts worse prognosis in digestive system tumors: a systemic review and meta-analysis. Biosci Rep. 2018b. 38: BSR20180169.

Lv GY, Miao J, Zhang XL. Long non-coding RNA XIST promotes osteosarcoma progression by targeting Ras-related protein RAP2B via miR-320b. Oncol Res. 2018. 26: 837-846.

Ma W, Wang H, Jing W, Zhou F, Chang L, Hong Z, Liu H, Liu Z, Yuan Y. Downregulation of long non-coding RNAs JPX and XIST is associated with the prognosis of hepatocellular carcinoma. Clin Res Hepatol Gastroenterol. 2017a. 41: 163-170.

Ma L, Zhou Y, Luo X, Gao H, Deng X, Jiang Y. Long non-coding RNA XIST promotes cell growth and invasion through regulating miR-497/MACC1 axis in gastric cancer. Oncotarget. 2017b. 8: 4125-4135.

Mo Y, Lu Y, Wang P, Huang S, He L, Li D, Li F, Huang J, Lin X, Li $\mathrm{X}$, Che S, Chen Q. Long non-coding RNA XIST promotes cell growth by regulating miR-139-5p/PDK1/AKT axis in hepatocellular carcinoma. Tumour Biol. 2017. 39: 1010428317690999.

Schouten PC, Vollebergh MA, Opdam M, Jonkers M, Loden M, Wesseling J, Hauptmann M, Linn SC. High XIST and low 53BP1 expression predict poor outcome after high-dose alkylating chemotherapy in patients with a BRCA1-like breast cancer. Mol Cancer Ther. 2016. 15: 190-198.

Song H, He P, Shao T, Li Y, Li J, Zhang Y. Long non-coding RNA XIST functions as an oncogene in human colorectal cancer by targeting miR-132-3p. J BUON. 2017. 22: 696-703.

Song P, Ye LF, Zhang C, Peng T, Zhou XH. Long non-coding RNA XIST exerts oncogenic functions in human nasopharyngeal carcinoma by targeting miR-34a-5p. Gene. 2016. 592: 8-14.

Sun J, Pan LM, Chen LB, Wang Y. LncRNA XIST promotes human lung adenocarcinoma cells to cisplatin resistance via let-7i/ BAG-1 axis. Cell Cycle. 2017a. 16: 2100-2107.

Sun Z, Zhang B, Cui T. Long non-coding RNA XIST exerts oncogenic functions in pancreatic cancer via miR-34a-5p. Oncol Rep. 2018a. 39: 1591-1600.

Sun N, Zhang G, Liu Y. Long non-coding RNA XIST sponges miR-34a to promote colon cancer progression via Wnt/betacatenin signaling pathway. Gene. 2018b. 665: 141-148.

Sun W, Zu Y, Fu X, Deng Y. Knockdown of lncRNA-XIST enhances the chemosensitivity of NSCLC cells via suppres- 
sion of autophagy. Oncol Rep. 2017b. 38: 3347-3354.

Tang Y, He R, An J, Deng P, Huang L, Yang W. lncRNA XIST interacts with miR-140 to modulate lung cancer growth by targeting iASPP. Oncol Rep. 2017. 38: 941-948.

Thomson DW, Dinger ME. Endogenous microRNA sponges: evidence and controversy. Nat Rev Genet. 2016. 17: 272-283.

Wang H, Shen Q, Zhang X, Yang C, Cui S, Sun Y, Wang L, Fan X, $\mathrm{Xu}$ S. The long non-coding RNA XIST controls non-small cell lung cancer proliferation and invasion by modulating miR-186-5p. Cell Physiol Biochem. 2017a. 41: 2221-2229.

Wang Z, Yuan J, Li L, Yang Y, Xu X, Wang Y. Long non-coding RNA XIST exerts oncogenic functions in human glioma by targeting miR-137. Am J Transl Res. 2017b. 9: 1845-1855.

Wang X, Zhang G, Cheng Z, Dai L, Jia L, Jing X, Wang H, Zhang R, Liu M, Jiang T, Yang Y, Yang M. Knockdown of LncRNAXIST suppresses proliferation and TGF-beta1-induced EMT in NSCLC through the Notch-1 pathway by regulation of miR-137. Genet Test Mol Biomarkers. 2018. 22: 333-342.

Wei W, Liu Y, Lu Y, Yang B, Tang L. LncRNA XIST promotes pancreatic cancer proliferation through miR-133a/EGFR. J Cell Biochem. 2017. 118: 3349-3358.

Xiao Y, Yurievich UA, Yosypovych SV. Long noncoding RNA XIST is a prognostic factor in colorectal cancer and inhibits 5-fluorouracil-induced cell cytotoxicity through promoting thymidylate synthase expression. Oncotarget. 2017. 8: 83171 -83182 .

Xiong Y, Wang L, Li Y, Chen M, He W, Qi L. The Long NonCoding RNA XIST interacted with MiR-124 to modulate bladder cancer growth, invasion and migration by targeting androgen receptor (AR). Cell Physiol Biochem. 2017. 43: 405 -418 .

Xu T, Jiang W, Fan L, Gao Q, Li G. Upregulation of long noncoding RNA Xist promotes proliferation of osteosarcoma by epigenetic silencing of P21. Oncotarget. 2017a. 8: 101406101417.

Xu Z, Xu J, Lu H, Lin B, Cai S, Guo J, Zang F, Chen R. LARP1 is regulated by the XIST/miR-374a axis and functions as an oncogene in non-small cell lung carcinoma. Oncol Rep. 2017b. 38: 3659-3667.

Xu R, Zhu X, Chen F, Huang C, Ai K, Wu H, Zhang L, Zhao X. LncRNA XIST/miR-200c regulates the stemness properties and tumourigenicity of human bladder cancer stem cell-like cells. Cancer Cell Int. 2018. 18: 41.
Yang C, Wu K, Wang S, Wei G. Long non-coding RNA XIST promotes osteosarcoma progression by targeting YAP via miR-195-5p. J Cell Biochem. 2018. 119: 5646-5656.

Yao Y, Ma J, Xue Y, Wang P, Li Z, Liu J, Chen L, Xi Z, Teng H, Wang Z, Li Z, Liu Y. Knockdown of long non-coding RNA XIST exerts tumor-suppressive functions in human glioblastoma stem cells by up-regulating miR-152. Cancer Lett. 2015. 359: 75-86.

Yu H, Xue Y, Wang P, Liu X, Ma J, Zheng J, Li Z, Li Z, Cai H, Liu Y. Knockdown of long non-coding RNA XIST increases blood-tumor barrier permeability and inhibits glioma angiogenesis by targeting miR-137. Oncogenesis. 2017. 6: e303.

Zhang Q, Chen B, Liu P, Yang J. XIST promotes gastric cancer (GC) progression through TGF-betal via targeting miR-185. J Cell Biochem. 2018. 119: 2787-2796.

Zhang R, Xia T. Long non-coding RNA XIST regulates PDCD4 expression by interacting with miR-21-5p and inhibits osteosarcoma cell growth and metastasis. Int J Oncol. 2017. 51: 1460-1470.

Zhang YL, Li XB, Hou YX, Fang NZ, You JC, Zhou QH. The IncRNA XIST exhibits oncogenic properties via regulation of miR-449a and Bcl-2 in human non-small cell lung cancer. Acta Pharmacol Sin. 2017. 38: 371-381.

Zheng R, Lin S, Guan L, Yuan H, Liu K, Liu C, Ye W, Liao Y, Jia J, Zhang R. Long non-coding RNA XIST inhibited breast cancer cell growth, migration, and invasion via miR-155/ CDX1 axis. Biochem Biophys Res Commun. 2018. 498: 1002 -1008 .

Zhuang LK, Yang YT, Ma X, Han B, Wang ZS, Zhao QY, Wu LQ, Qu ZQ. MicroRNA-92b promotes hepatocellular carcinoma progression by targeting Smad7 and is mediated by long non-coding RNA XIST. Cell Death Dis. 2016. 7: e2203.

Zhu H, Zheng T, Yu J, Zhou L, Wang L. LncRNA XIST accelerates cervical cancer progression via upregulating Fus through competitively binding with miR-200a. Biomed Pharmacother. 2018. 105: 789-797.

https://doi.org/10.15616/BSL.2019.25.2.113

Cite this article as: Madhi $\mathrm{H}$, Kim MH. Beyond X-Chromosome Inactivation: The Oncogenic Facet of XIST in Human Cancers. Biomedical Science Letters. 2019. 25: 113-122. 